known to favor these initial steps in proteolysis, while all salts, including stich "buffer" salts as phosphates or citrates, have been known to inhibit them. Their action has usually been laid to an effect upon the enzymes themselves. As has been pointed out before, acids, alkalies and salts produce at least as large and probably their greatest effects upon the proteins undergoing digestion. The important theoretical and practical bearings of such considerations upon laboratory practice and the everyday problems of the hanging of meat, its preservation by salting, the prevention of putrefaction, etc., are self-evident.

These experiments emphasize again the necessity of interpreting in the simpler language of colloid-chemistry the mass of experimental material now collected by the biologists under the heading of "permeability" studies. It means little to say that under the influence of acids or of substances which in living cells produce acid effects (like the anesthetics) the "permeability" of the "plasma" membranes surrounding cells is increased so that albumin gets out or salts get in. Not only are plasma membranes figments of the imagination, but nothing is gained by heaping "permeability" properties upon them. "Permeability" is a physiological concept which itself needs to be explained. The proteins throughout a cell (not only in its hypothetical overcoat) can under the influence of acids, for example, be made to absorb water, to absorb salt, ${ }^{1}$ to soften and to give off albumin. And as all these effects may be observed in simple proteins where their exact nature is more accessible to quantitative study and further analysis than in the case of our complex living cells, it would look like a better conservation of mental energy to concentrate further study upon the colloid-chemical principles here to the front than to continue indefinitely the mere restatement of biological problems in the terms of biology itself.

Cincinnati, OhIo.

[Contribution from the Hygienic Laboratory, U. S. Public Health Service.]

\title{
THE UTILIZATION OF THE ADSORPTIVE POWER OF FULLER'S EARTH FOR CHEMICAL SEPARATIONS.
}

By ATHERTON SETDELL.

Received November 12, 1917.

The utilization of fuller's earth for chemical separations (other than decolorizations) has, in recent years, found at least two practical applications. The first of these is its use in connection with the isolation of alkaloids $^{2}$ from plants or their extracts and the second forms an important

: Martin H. Fischer, J. Am. Med. Assoc., 64, 3.25 (1915).

2 Sigmund Waldbott, "Precipitating Alkaloids by Lloyd's Reagent-Preliminary Note," This Journal, 35,837 (IgI3). 
step in the more or less complete separation of "vitamines"1 from the complex mixtures in which they occur. In neither case has detailed information been given in regard to the particular conditions under which the adsorptive power can be utilized to best advantage. It was simply learned by empirical experiments, that if a sufficient amount of a particular variety of fuller's earth was shaken for a short time with a neutral or slightly acid solution containing an alkaloid or "vitamine," the filtrate from the mixture would fail to give a positive test for the one or the other as the case might be. No data are available on such matters as the effect on the adsorptive process of time, agitation, dilution, reaction, presence of other dissolved substances, variations in the proportion of earth used, etc.

The results of comparative tests of the adsorptive powers of fuller's earths from various sources have been published, ${ }^{2}$ but little information has been given in regard to the technic of the methods employed. These experiments showed that of all the samples tested, a particular variety of earth designated as "Lloyd's reagent" exerted the highest adsorptive power. Information in regard to the source of this earth and particulars concerning its preparation for use are not given. Although there was no reason to question the correctness of the results of the comparative tests referred to above, it was believed that additional data along this line, obtained by a more clearly defined method, would be of interest.

Relative Adsorptive Power of Various Fuller's Earths. - In the case of most of the previous experiments made in this connection, the basis for expressing the results has been the quantity of fuller's earth required to adsorb unit quantity of alkaloid. Since, however, it is a question of comparing the various samples of earth with each other, it was believed that a more direct estimate would be that based on the amount of alkaloid adsorbed by unit quantity of the various samples. This basis has, therefore, been adopted for the results here given.

Preliminary experiments showed that the adsorption process is not instantaneous and therefore that sufficient time of contact of solution with the solid must be allowed. Furthermore, since the bulk of the earth rapidly subsides on standing, it is necessary that continual agitation be employed.

Since the main object was a comparison of the fuller's earth samples with each other, the particular alkaloid used did not appear to be of consequence. Quinine bisulfate $\left(\mathrm{C}_{20} \mathrm{H}_{24} \mathrm{~N}_{2} \mathrm{O}_{2} \mathrm{H}_{2} \mathrm{SO}_{4} \cdot 7 \mathrm{H}_{2} \mathrm{O}\right)$ was, therefore, arbitrarily selected. In addition to the results obtained with quinine bisulfate, it was considered of interest to secure a series of comparative figures for another compound of different character. Methylene blue

${ }^{1}$ A. Seidell, Pub. Health Reports, 3I, 364 (1916).

2 Bernard Fantus, J. Am. Med. Assoc., 64, 1838 (I915); J. Uri Lloyd, J. Am. Pharm. Assoc. 5, 381, 490 (1916). 
(tetramethylthionine chloride, $\mathrm{C}_{18} \mathrm{H}_{18} \mathrm{~N}_{3} \mathrm{ClS} .{ }_{3} \mathrm{H}_{2} \mathrm{O}$ ) was selected for this purpose. Two series of results have, therefore, been obtained using exactly the same procedure in both cases, one showing the adsorption coefficients obtained with quinine bisulfate and the other with methylene blue.

The samples of fuller's earth were obtained from the several sources mentioned in Table I. Those from Chas. L. Parsons of the Bureau of Mines were collected by him some years ago for comparative cottonseed oil decolorization tests and additional information in regard to these is given in Parsons' publication. ${ }^{1}$ The samples ${ }^{2}$ as received were for the most part in the form of lumps, but in each case were ground to pass a No. 60 or finer mesh screen and thoroughly mixed before being used.

The method adopted for the tests was as follows: One gram portions of the fuller's earth sample and about to cc. of water were placed in a series of test tubes of $60 \mathrm{cc}$. or more capacity and, after thoroughly mixing, accurately measured volumes of $1.0 \%$ quinine bisulfate solution or $0.5 \%$ methylene blue solution were added. Rubber stoppers were inserted and the tubes attached to a frame which was kept in rotation for one-half hour. The contents of the tubes were then quickly filtered into other test tubes and the filtrates, in the case of the quinine bisulfate solutions, treated with about three drops of Mayer's alkaloidal reagent. Tests with a given sample of fuller's earth were repeated as above with increasing amounts of quinine bisulfate, until a quantity was found that yielded a filtrate in which a just perceptible clouding resulted on addition of the Mayer reagent. In the case of the methylene blue solutions the test was repeated until a just perceptible blue color could be detected in the filtrate. From the volumes of solutions of quinine bisulfate and methylene blue corresponding to these end points, the values in terms of grams of each compound adsorbed per Ioo g. of the fuller's earth sample were calculated and the results given in Table $I$.

The samples are arranged in this table according to descending amounts of quinine bisulfate adsorbed. It will be noted that, in general, there is a parallelism between the amounts of alkaloid and of methylene blue adsorbed. Also that with two or three exceptions the figure for methylene blue is somewhat higher than that for quinine bisulfate.

The samples of bentonite show particularly high adsorptive coefficients and would, therefore, be expected to be especially useful as absorbents. It is to be mentioned, however, that, from the manipulative standpoint, they have the practical disadvantage of taking up very large quantities of water to form gelatinous masses from which the aqueous solution cannot be completely separated by filtration or centrifugation. Although this

1 "FulLER's EARTH," Bureau of Mines, Bull. 7I, I9I3.

2 The author desires to acknowledge his indebtedness to all those who have contributed samples for these tests. 
property of bentonite no doubt makes it of great value for other purposes, it renders it less suitable for quantitative chemical separations.

Table I.-Adsorption Coefricients of Fuller's Earths and Other Clays ExPRESSED IN TERMS OF G. OF QUININE BISULFATE AND OF METHYLENE

BLUE ADSORBED PER IOO G. OF EACH SAMPLE.

(Volume of solution, about $30 \mathrm{cc}$. in each case; time of contact at constant agitation, one-half hour.)

Description of sample.

Bentonite, Newcastle, Wyo:......... F. W. Mondell

Bentonite, Wyoming.............. National Museum

Fuller's earth, Utah............... National Museum

Bentonite, Halleck, Cal. ........... R. B. Flenniken

Fuller's earth, Surrey, England......... Eimer \& Amend

"Lloyd's reagent" (white).............. J. U. Lloyd

"Lloyd's reagent"................... J. U. Lloyd

Fuller's earth (red), Buckingham, Eng... . National Museum

Fuller's earth (gray), Buckingham, Eng... National Museum

Fuller's earth, English.............. Chas. L. Parsons

Fuller's earth, Custer Co., S. D........ National Museum

Fuller's earth ................... A. H. Thomas \& Co.

Fuller's earth.................... Shoemaker \& Busch

Bentonite, Utah................ National Museum

Fuller's earth, Sommerville, Tex........ H. C. Gore

Fuller's earth, Carlton, Ga........... Chas. L. Parsons

Dark clay (prob. Bentonite), Halleck, Cal. R. B. Flenniken

Fuller's earth (old sample), Carlton, Ga... Chas. L. Parsons

Fuller's earth, Fitzpatrick, Ga........ Chas. I. Parsons

Fuller's earth, Vacaville, Cal........... Chas. L. Parsons

Fuller's earth, Moultrie, Ga.......... Chas. L. Parsons

Fuller's earth, Attapulgus, Ga......... Chas. I. Parsons

Fuller's earth, Sumpter, S. C......... Chas. L. Parsons

Fuller's earth................... Scientific Materials Co.

Fuller's earth, Benton, Ark.......... H. C. Gore

Clay No. I, Kingsbury.............. Chas. I. Parsons

Fuller's earth (ignited) ............. Texas Oil Co.

Fuller's earth, Midway, Fla............ Chas. L. Parsons

Fuller's earth, Ellenton, Fla.......... Chas. L. Parsons

Fuller's earth, Ellenton, Fla.......... Chas. L. Parsons

Kieselguhr....................

Fuller's earth, Ft. Payne, Ala..........

Fuller's earth, Andalusia, Ala..........

Fuller's earth, Lancaster, Mass..........

Halloysite, Utah.

Fuller's earth(?)
A. H. Thomas \& Co.

Chas. L. Parsons

Chas. L. Parsons

Chas. L. Parsons

National Museum

Bausch \& Lomb
Adsorption coefficients.

Quinine Methylene
bisulfate. $\begin{gathered}\text { Methylen } \\ \text { blue. }\end{gathered}$

$20.0 \quad 18.0$

$18.0 \quad 27.8$

$17.5 \quad 18.7$

$16.0 \quad 18.0$

I6.0 16.0

$15.5 \quad 23.8$

I5.5 17.8

$\begin{array}{ll}15.0 & 14.8\end{array}$

I5.O $\quad$ I 3.8

$15.0 \quad 13.5$

I2. $5 \quad 15.0$

I $2.0 \quad 14.8$

I2.0 $\quad 14.8$

I2.0 22.5

$8.0 \quad 10.0$

$\begin{array}{ll}7.8 & 9.9\end{array}$

$7.0 \quad 9.0$

$6.5 \quad 8.0$

$\begin{array}{ll}6.0 & 9.8\end{array}$

$5.0 \quad 8.5$

$4.0 \quad 6.0$

$3.5 \quad 5.7$

$3.5 \quad 5.4$

$3.5 \quad 5.8$

$2.5 \quad 3.0$

I. $5 \quad 2.4$

I. $5 \quad 3.4$

I. $3 \quad 2.9$

I. 3.3

I. $2 \quad 3.7$

I. 2 I. 8

I.O $\quad$ I. 7

$0.4 \quad$ I. 2

$0.3 \quad 0.7$

$0.3 \quad 1.0$

0.20 .2

In regard to the results obtained with the fuller's earth samples, it is seen that all of those from England have very nearly the same coefficient for quinine bisulfate and this figure is very close to that found for "Lloyd's reagent." The American samples, with the exception of the one from 
Utah for which further details in regard to its origin could not be obtained, have distinctly lower adsorption coefficients. In the case of some of these it is possible that by proper treatment for removal of inactive portions, products of higher coefficients could be prepared. The English earth is, however, readily obtainable and evidently of very uniform adsorptive power since various samples of it, which have so far been examined, show values in close agreement with those recorded in the table.

Effect of Time on Rate of Adsorption.-As already mentioned, preliminary experiments showed that the process of adsorption is not instantaneous and consequently that sufficient time must be allowed for attainment of equilibrium. The following experiments were, therefore, made to obtain data on this point:

The results of the first experiment are shown in Table II and Chart I. In this case, ro cc. portions of a I per cent. quinine bisulfate solution and different amounts of English fuller's earth mixed with about $20 \mathrm{cc}$. of water, were shaken at intervals for the periods shown, and the mixtures quickly filtered. The filtrates were tested with Mayers' reagent and the completeness of the adsorption judged by the extent of clouding which resulted. A summary is given in the lower part of the table showing the TAble II.-EFFect of Time on ADSorption of Quinine Bisulfate bX ENGlish FULLER'S EARTH (E. \& A.).

Composition of mixture in grams.

\begin{tabular}{|c|c|c|c|c|}
\hline $\begin{array}{l}\text { Quinine } \\
\text { bisulfate. }\end{array}$ & $\begin{array}{l}\text { Fuller's } \\
\text { earth. }\end{array}$ & $\mathrm{H}_{8} \mathrm{O}$ & $\begin{array}{l}\text { of contact, } \\
\text { minutes. }\end{array}$ & $\begin{array}{c}\text { Appearance of filtrate } \\
\text { on addition of Mayer's reagent. }\end{array}$ \\
\hline 0.1 & 0.7 & 30 & 5 & Immediate clouding \\
\hline $0 . I$ & 0.7 & 30 & 10 & Clouding less than preceding \\
\hline 0.1 & 0.7 & 30 & 15 & Very faint clouding \\
\hline $0 . I$ & 0.675 & 30 & I5 & Faint clouding \\
\hline 0.1 & 0.675 & 30 & 20 & Very faint clouding \\
\hline $0 . I$ & 0.633 & 30 & 40 & Faint clouding \\
\hline 0.1 & 0.625 & 30 & 60 & Clear \\
\hline 0.1 & 0.600 & 30 & 60 & Cloudy \\
\hline 0.1 & 0.610 & 30 & 80 & Very faint clouding \\
\hline 0.1 & 0.600 & 30 & I 20 & Cloudy \\
\hline 0.1 & 0.600 & 30 & 20 hours & Clear \\
\hline 0.1 & 0.575 & 30 & 20 hours & Very faint clouding \\
\hline 0.1 & 0.550 & 30 & 20 hours & Cloudy \\
\hline
\end{tabular}

SUMMARy OF THE ABOVE.

\begin{tabular}{|c|c|c|}
\hline Time. & $\begin{array}{l}\text { G. fuller's earth to just adsorb } \\
0.1 \mathrm{~g} \text {. quinine bisulfate. }\end{array}$ & $\begin{array}{l}\text { Calc. g. quinine bi- } \\
\text { sulfate just adsorbed } \\
\text { per } 100 \mathrm{~g} \text {. fuller's earth. }\end{array}$ \\
\hline I5 minutes. & $\ldots \ldots \ldots \quad 0.7$ & 14.3 \\
\hline 20 minutes. & $\ldots \ldots .675$ & 14.8 \\
\hline 40 minutes. & $\ldots \ldots \quad 0.633$ & $\mathrm{r} 5.8$ \\
\hline 60 minutes. & $\ldots \ldots \quad 0.625$ (slightly high) & 16.0 \\
\hline 80 minutes. & $\ldots \ldots 0.6 \mathrm{I}$ & 16.5 \\
\hline I 20 minutes. & $\ldots \quad 0.600$ (slightly low) & 16.7 \\
\hline 20 hours. . & $\ldots \ldots \ldots \ldots 0.575$ & 17.4 \\
\hline
\end{tabular}


amounts of fuller's earth required, on the basis of the qualitative test for unadsorbed alkaloid, to just completely adsorb o. I g. of quinine bisulfate in the several periods of time. The reciprocals of these values $(X 100)$ showing the grams of quinine bisulfate which would be just adsorbed by I00 g. of fuller's earth in the time stated, are also given. These latter values, together with the results obtained with methylene blue, are plotted in Chart I.

The experiments with methylene blue were made as follows: A number of tubes were prepared containing the same ratio of methylene blue to fuller's earth in each. These were rotated for different lengths of time and the unadsorbed methylene blue estimated in the filtrate from each mixture by a colorimetric comparison. The quantities thus found were deducted from the methylene blue originally present and the amount adsorbed thus calculated by difference. Results are given in Table III for two different ratios of methylene blue to fuller's earth. For the purpose of comparing with the preceding experiment, the figures are also calculated to grams of methylene blue adsorbed by Ioo g. of fuller's earth. These values, together with the corresponding results obtained with quinine bisulfate are plotted in Chart I. They show strikingly, that the rate of adsorption is very greatly accelerated by increase of excess of material to be adsorbed.

Table III.-EFfect of Time on Adsorption of Methylene Blue by ENGlish FULLER's EARTH (E. \& A.).

\begin{tabular}{|c|c|c|c|c|c|c|}
\hline \multirow[b]{2}{*}{ Series. } & \multicolumn{3}{|c|}{$\begin{array}{l}\text { Composition of original } \\
\text { mixture in } \mathrm{g} \text {. }\end{array}$} & \multirow{2}{*}{$\begin{array}{c}\text { Time of } \\
\text { constant } \\
\text { agitation. } \\
\text { (Min.). }\end{array}$} & \multicolumn{2}{|c|}{$\begin{array}{l}\text { G. methylene blue } \\
\text { adsorbed. }\end{array}$} \\
\hline & Fuller's & $\underbrace{}_{\begin{array}{c}\text { Methylene } \\
\text { blue. }\end{array}}$ & $\mathrm{H}_{2} \mathrm{O}$. & & $\begin{array}{c}\text { Per } 0.25 \mathrm{~g} \\
\text { fuller's } \\
\text { earth. }\end{array}$ & $\begin{array}{c}\text { Per } 100,8 \\
\text { fuller's } \\
\text { earth. }\end{array}$ \\
\hline \multirow[t]{4}{*}{ I $\ldots \ldots$} & 0.25 & 0.045 & 30 & Io & 0.0388 & $\mathrm{I}_{5} \cdot 52$ \\
\hline & 0.25 & 0.045 & 30 & 30 & 0.0436 & I 7.44 \\
\hline & 0.25 & 0.045 & 30 & 60 & 0.0446 & 17.84 \\
\hline & 0.25 & 0.045 & 30 & 120 & 0.0449 & 17.96 \\
\hline \multirow[t]{4}{*}{ II . . . . } & 0.25 & 0.075 & 30 & 10 & 0.0450 & 18.00 \\
\hline & 0.25 & 0.075 & 30 & 30 & 0.0557 & 22.28 \\
\hline & 0.25 & 0.075 & 30 & 60 & 0.0564 & 22.56 \\
\hline & 0.25 & 0.075 & 30 & 120 & 0.0569 & 22.76 \\
\hline
\end{tabular}

It is to be noted that in the case of the methylene blue experiment, a fairly large excess was used in one case and a smaller but considerable excess in the other, whereas with the quinine bisulfate no greater excess was present than sufficient to permit the detection of the end point. The curves given in Chart I show that the rate of adsorption is proportional to the excess of material to be adsorbed. The question of the selection of the proper time to be allowed for adsorption in practical work is, therefore, complicated by this factor of influence of excess of adsorbable material present. The curve for quinine bisulfate represents exactly the conditions selected for making the comparisons of the various fuller's earth samples as 
shown in Table $I$; that is, the end point representing no excess of material to be adsorbed. This curve rises most gradually of all and no relatively short time period can be selected from it as having a particular advantage over another. The one-half hour period which was arbitrarily selected

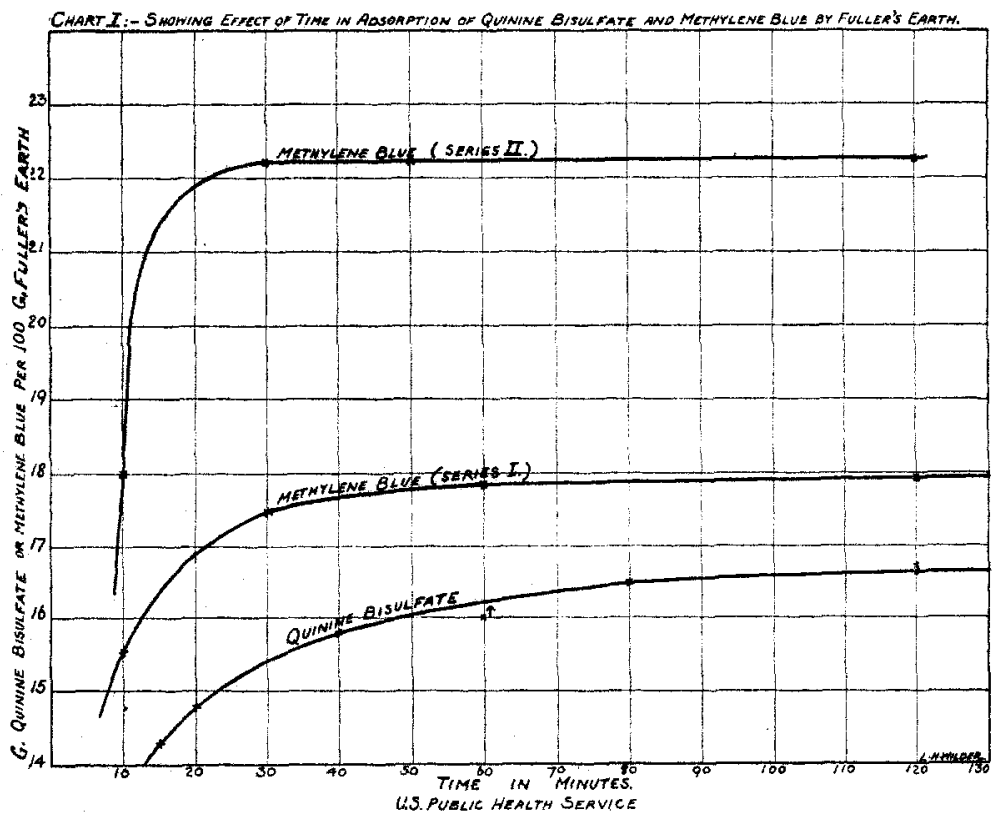

for the comparative tests already described has, no doubt, given as trustworthy results as would have been obtained by a longer period. The curve here shown, however, emphasizes strongly the necessity for a rigid control of the time factor in comparing various samples of fuller's earth.

Effect of Excess of Methylene Blue and of Quinine Bisulfate upon Their Adsorption by Fuller's Earth.-Since, as shown in the preceding section, the rapidity of the adsorption is greatly increased by excess of methylene blue, it appeared of interest to ascertain the effect of this factor on the quantity of methylene blue and of quinine bisulfate adsorbed.

In the case of this and all other experiments with methylene blue, a sample was used which contained $0.87 \%$ ash and in other respects conformed to the pharmacopoeial requirements for tetramethylthionine chloride $\left(\mathrm{C}_{18} \mathrm{H}_{18} \mathrm{~N}_{8} \mathrm{ClS}_{3} \mathrm{H}_{2} \mathrm{O}\right)$. Gradually increasing amounts of a solution of this product were added to accurately weighed portions of English fuller's earth (E. \& A.), to yield mixtures of the compositions shown in Table IV, and these constantly agitated for one-half hour. They were then quickly centrifugated and aliquot portions of the clear supernatant solutions removed for determination of the unadsorbed methylene blue 
by a colorimetric comparison. Centrifugation was employed rather than filtration since it was found that considerable color is removed from the solution by the paper filters. The results of this experiment are given in Table IV and shown graphically in Chart II.

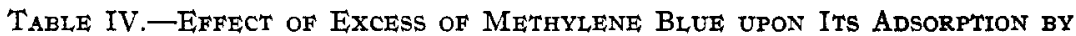
FuLLER's EARTH.

(Mixtures constantly agitated for one-half hour.)

Composition of original mixture in $\mathrm{g}$.

$\begin{gathered}\text { Fuller's } \\ \text { earth. }\end{gathered}$
$\begin{gathered}\text { Methylene } \\ \text { blue. }\end{gathered}$

$\begin{array}{lll}0.5 & 0.065 & 30 \\ 0.5 & 0.070 & 30 \\ 0.5 & 0.0725 & 30 \\ 0.5 & 0.080 & 30 \\ 0.5 & 0.090 & 30 \\ 0.5 & 0.100 & 30 \\ 0.5 & 0.125 & 30 \\ 0.5 & 0.150 & 60 \\ 0.5 & 0.200 & 60 \\ 0.5 & 0.300 & 60\end{array}$

G. methylene blue calculated to $100 \mathrm{~g}$. fuller's earth.

$\begin{array}{ccc}\begin{array}{c}\text { Originally } \\ \text { present. }\end{array} & \begin{array}{c}\text { Unadsorbed (det. } \\ \text { colorimetrically). }\end{array} & \begin{array}{c}\text { Adsorbed. } \\ \text { (calc. by diff.). }\end{array} \\ 13.0 & 0.013 & 12.987 \\ 14.0 & 0.020 & 13.980 \\ 14.5 & 0.022 & 14.478 \\ 16.0 & 0.055 & 15.945 \\ 18.0 & 0.270 & 17.730 \\ 20.0 & 0.915 & 19.085 \\ 25.0 & 3.75 & 21.250 \\ 30.0 & 7.73 & 22.280 \\ 40.0 & 16.00 & 24.000 \\ 60.0 & 33.60 & 26.400\end{array}$

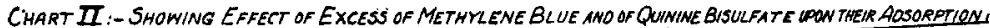

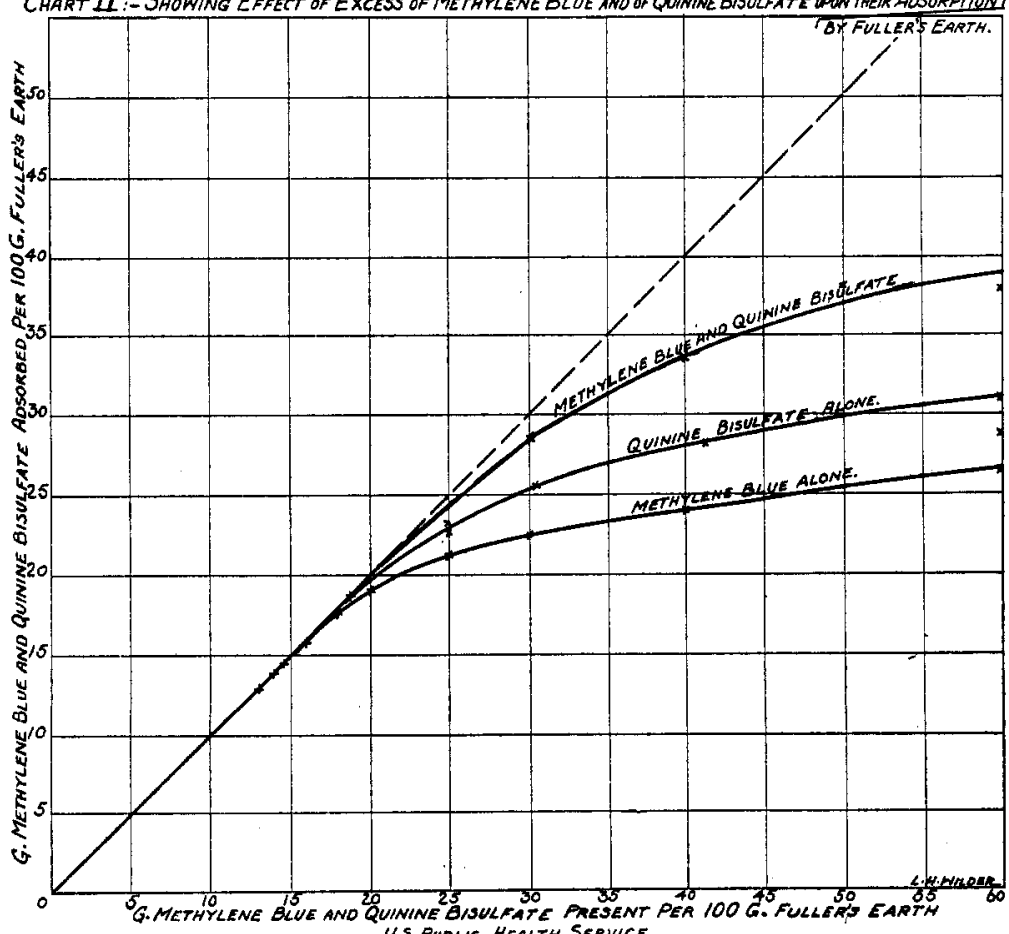

U.S. PUBLIE health SERVICE.

It is seen that the amount of methylene blue adsorbed continues to increase with each additional increment of coloring matter in solution but 
the rate of increase gradually diminishes. There appears to be no definite limit for the total amount of the compound which can be adsorbed per unit of fuller's earth.

Considerable difficulty has been experienced in preparing a chart which would exhibit clearly the change in the adsorption due to increasing excess of adsorbable color. It is evident that up to a certain point all of the methylene blue is completely adsorbed. There is, however, no sharp break at this point. The amount of color adsorbed from this point on represents a gradually diminishing fraction of that present. The unadsorbed fraction, therefore, begins as a mere trace at a certain point which obviously cannot be accurately determined, and increases almost imperceptibly at first, and then more and more rapidly. On this account, it follows that, in attempting to ascertain the adsorptive capacity of a given sample of fuller's earth by determination of the maximum amount of methylene blue which will be just completely adsorbed by it within a definite time, the end point of the test comes at exactly that part of the curve where very small differences in the estimated amount of unadsorbed color correspond to relatively large differences in amount adsorbed. Furthermore, errors due to filtering through paper, to which attention has already been called, are accentuated at this portion of the curve. The magnitude of the error due to filter paper is indicated by comparing the adsorption coefficient given in Table I for the sample of fuller's earth used in the present experiment (Surrey, England, E. \& A.) with the coefficient which is derived from Table IV. In the one case, filtration through paper was used and the value was found to be $16 \mathrm{~g}$. methylene blue per $100 \mathrm{~g}$. of the sample, while in the other, in which removal of the solid was effected by centrifugation, it would be placed at slightly less than $I_{3} \mathrm{~g}$. For these and other reasons, it is apparent that the values given in Table I for the adsorption coefficients of various samples of fuller's earth can be considered of interest only as showing the relative position of the several samples in the series. Even the very great care which was exercised to maintain uniform conditions could not be expected to overcome the limitations of the test described above.

In order to gain some information in regard to how firmly the methylene blue is combined with the fuller's earth when the combination has been made in the presence of the very considerable excesses of methylene blue shown in Table IV, the residues left in the centrifuge tubes after decantation of the clear liquids were, without washing, stirred up with $30 \mathrm{cc}$. portions of water. The mixtures were constantly agitated for one-half hour and then allowed to stand two days. The methylene blue in the supernatant liquids was then estimated colorimetrically as before. The results calculated to the basis of $\mathrm{g}$. per Ioo $\mathrm{g}$. fuller's earth are, respectively, 0.0004 , $0.0005,0.0005,0.0012,0.0050,0.0145,0.050,0.100,0.342$ and 0.732 . 
These amounts are no greater than could be accounted for by methylene blue solution mechanically held by the residues in the centrifuge tubes. It, therefore, seems probable that methylene blue adsorbed by fuller's earth in presence of a large excess of the color is held just as firmly as that taken up from less concentrated solutions.

The experiment with quinine bisulfate was made as described above for methylene blue. The mixtures were rotated for one-half hour, the suspended solid thrown down by centrifugation and the unadsorbed quinine bisulfate remaining in the clear supernatant solution titrated with $0.02 \mathrm{~N}$ sodium hydroxide, using phenolphthalein as indicator. The results are given in Table $\mathrm{V}$ and plotted in Chart II. The curve lies somewhat above that for methylene blue but is similar to it.

\begin{tabular}{|c|c|c|c|c|c|c|}
\hline \multirow[t]{3}{*}{ TABLE } & \multicolumn{6}{|c|}{$\begin{array}{l}\text { FULLER'S EARTH. } \\
\text { (Mixtures constantly agitated for one-half hour.) }\end{array}$} \\
\hline & \multicolumn{3}{|c|}{$\begin{array}{l}\text { Composition of original } \\
\text { mixture in } g \text {. }\end{array}$} & \multicolumn{3}{|c|}{$\begin{array}{l}\text { G. quinine bisulfate calculated to } \\
100 \mathrm{~g} \text {. fuller's earth. }\end{array}$} \\
\hline & $\begin{array}{l}\text { Fuller's } \\
\text { earth. }\end{array}$ & $\begin{array}{l}\text { Quinine } \\
\text { bisulfate. }\end{array}$ & $\mathrm{H}_{2} \mathrm{O}$. & $\begin{array}{l}\text { Originally } \\
\text { present. }\end{array}$ & $\begin{array}{l}\text { Unadsorbed (det. } \\
\text { volumetrically). }\end{array}$ & $\begin{array}{l}\text { Adsorbed } \\
\text { (calc. by diff.). }\end{array}$ \\
\hline I... & 0.5 & 0.093 & 30 & 18.6 & Trace & 18.6 \\
\hline I....... & 0.5 & 0.124 & 30 & 24.8 & I. 6 & 23.2 \\
\hline$I \ldots \ldots \ldots$ & 0.5 & 0.206 & 30 & $4 I .24$ & 12.94 & $28 \cdot 3$ \\
\hline I........ & 0.5 & 0.309 & 30 & 60.17 & 30.90 & 30.9 \\
\hline II $\ldots \ldots$ & I.O & 0.185 & 40 & 18.5 & Trace & I8. 5 \\
\hline II $\ldots \ldots$ & I.O & 0.247 & 40 & $24 \cdot 7$ & 2.0 & $22 \cdot 7$ \\
\hline II ....... & I.O & 0.309 & 40 & 30.9 & $5 \cdot I$ & 25.8 \\
\hline II $\ldots \ldots$ & 0.5 & 0.309 & 40 & 60.18 & 32.4 & 27.8 \\
\hline
\end{tabular}

Evidence that the Free Base Only Is Adsorbed when Solutions of Methylene Blue and Quinine Bisulfate are Placed in Contact with Fuller's Earth.-In the case of the second series of experiments recorded in Table $\mathrm{V}$ an aliquot of each supernatant solution was evaporated to dryness on the steam bath. It was found that the residues thus obtained weighed more than the quinine bisulfate calculated from the volumetric determinations. In the case of the first mixture of this second series in which only a trace of unadsorbed quinine remained in the aqueous solution, it was found that the residue obtained on evaporation consisted of nearly pure calcium sulfate. The amount of sulfate radical present in the residue corresponded almost exactly with that calculated from the amount of quinine adsorbed. It is, therefore, evident that when quinine bisulfate is shaken with fuller's earth, the quinine only unites with the earth and the acid is liberated.

A similar experiment was made with methylene blue and it was ascertained that here also only the free base is adsorbed and a chloride remains behind in the aqueous solution. The analytical results were obtained on a solution (Table IV, first mixture) containing only a trace of unadsorbed 
methylene blue and showed that the amount of chloride remaining in the aqueous solution agreed closely with that originally in combination with methylene blue. The aqueous solution also contained calcium, thus indicating that also in this case the liberated acid is neutralized by the calcium of the fuller's earth. A confirmatory test of the absence of chloride in the methylene blue adsorbed to fuller's earth was made by igniting a portion of the dried product in the presence of alkali carbonate, extracting with water, acidifying and adding silver nitrate. A very faint opalescence showed that not more than a trace of chloride was present. Although the above experiments show that only the free base unites with the fuller's earth in each case, the figures in all the tables are, for convenience, given in terms of the weight of the original compound adsorbed and remaining unadsorbed.

The Simultaneous Adsorption of Quinine Bisulfate and Methylene Blue by Fuller's Earth.- Since the preceding experiments have shown the amounts of quinine bisulfate and of methylene blue which are adsorbed when each is present separately, it appeared of interest to ascertain how much of each is adsorbed when both are simultaneously present in equal amounts, and thus to determine whether fuller's earth shows any selective action in the adsorption of one or the other of these two compounds.

Table VI.-Simultaneous Adsorption of Merhylene Blue and Quinine BISULFATE BY FULLER'S EARTH.

(Mixtures constantly agitated for one-half hour.) Composition of original mixture in $\mathrm{g}$.

$\begin{array}{cccc}\text { Fuller's } & \begin{array}{c}\text { Methylene } \\ \text { blue. }\end{array} & \begin{array}{c}\text { Quinine } \\ \text { bisulfate. }\end{array} & \text { H.O. } \\ \text { I.O } & 0.05 & 0.05 & 100 \\ 1.0 & 0.10 & 0.10 & 100 \\ 1.0 & 0.15 & 0.15 & 100 \\ \text { I:O } & 0.20 & 0.20 & 100 \\ \text { I.O } & 0.25 & 0.25 & 100 \\ 1.0 & 0.30 & 0.30 & 100\end{array}$

G. adsorbed per 1.0 g. fuller's earth.

$\begin{array}{lcl}\begin{array}{c}\text { Methylene } \\ \text { blue. }\end{array} & \begin{array}{c}\text { Quinine } \\ \text { bisulfate. }\end{array} & \text { Total. } \\ 0.05 & 0.05 & 0.10 \\ 0.10 & 0.10 & 0.20 \\ 0.149 & 0.136 & 0.285 \\ 0.173 & 0.162 & 0.335 \\ 0.182 & 0.197 & 0.379 \\ 0.186 & 0.192 & 0.378\end{array}$

With the above object in view, mixtures of the compositions shown in Table VI were prepared and rotated for one-half hour as in the previous experiments. The solid was thrown down by centrifugation and the decanted clear liquids used for determination of the amounts of the two compounds remaining unadsorbed. An aliquot portion in each case was first used for the estimation of methylene blue by a colorimetric comparison. Another aliquot portion was evaporated to dryness on the steam bath and the residue weighed. As pointed out in the preceding section, this residue contains not only the unadsorbed quinine bisulfate and methylene blue but also calcium sulfate and chloride equivalent, respectively, to the amounts of each free base adsorbed. The amount of methylene blue in the evaporated residues was, as mentioned above, ascertained from the 
colorimetric comparison of the separate portion of the solution. No method of isolating the quinine bisulfate from the mixture or of estimating it in the presence of the methylene blue has, so far, been devised. Immiscible solvents fail to effect a separation in either acid or alkaline solution. It was therefore necessary to rely upon an indirect procedure for estimating the amount of this constituent which remained unadsorbed. This was done, in the present case, in two ways, first by treating each residue with absolute alcohol and filtering through a weighed Gooch funnel. From the weight of calcium sulfate thus separated, the adsorbed quinine was calculated directly. Secondly, the sum of the determined methylene blue and calcium sulfate and of the estimated calcium chloride (from methylene blue adsorbed) was deducted from the total weight of the residue and the difference assumed to be quinine bisulfate. The values for unadsorbed quinine bisulfate obtained by these two indirect methods agree fairly satisfactorily and from them the results shown in Table VI have been calculated. It is seen that nearly equal amounts of the two substances are adsorbed in each case. The sum of the two is considerably greater than the amount of either adsorbed separately.

The figures representing these totals (multiplied by 100) have been plotted in Chart II. They illustrate the magnitude of this increase of adsorptive capacity resulting from the simultaneous presence of the two compounds over that found for either one separately. The results also indicate that fuller's earth shows no marked preference for either compound when approximately equal amounts of the two are simultaneously present in solution.

The Successive Adsorption of Methylene Blue and Quinine Bisulfate by a Single Portion of Fuller's Earth. - These experiments were made by first shaking given solutions of one of the compounds with fuller's earth and after removing the solid by centrifugation, adding solutions of known amounts of the other compound and proceding just as before. The supernatant solutions were analyzed in both cases and the amounts of each compound uniting with fuller's earth, or displaced from it as the case might be, determined by difference. The results of these experiments are given in Tables VII and VIII. From these it is seen that, when fuller's earth containing adsorbed methylene blue is shaken with quinine bisulfate solutions, practically none of the methylene blue is displaced from its combination with fuller's earth and the amounts of quinine bisulfate adsorbed decrease with the increasing amounts of methylene blue united to the fuller's earth. On the other hand, when the procedure is reversed, methylene blue is not only adsorbed in proportion to the increasing amount of it present, but it even displaces a considerable part of the quinine bisulfate from its combination with the fuller's earth. In this latter case the total amount of the two compounds finally present agrees well with the totals 
found in the experiment described in the preceding section and plotted in Chart II, showing the amounts of the two compounds simultaneously adsorbed from solution. On the basis of the present results it appears that, under the conditions here described, fuller's earth exhibits a stronger affinity for methylene blue than for quinine bisulfate. This difference is, however, certainly not of sufficient magnitude to be utilized in separating one of the compounds from the other.

Table VII.-ADsorption of Quinine Bisulfate by Fulieg's Earth Containing Adsorbed Methylene Blue.

\begin{tabular}{|c|c|c|c|c|c|c|}
\hline \multirow{3}{*}{$\begin{array}{l}\text { G. } \\
\text { original } \\
\text { fuller's } \\
\text { eart!. }\end{array}$} & & \multirow{3}{*}{$\begin{array}{c}\text { Total g. } \\
\text { methylene } \\
\text { blue + } \\
\text { quinine } \\
\text { bisulfate } \\
\text { adsorbed. }\end{array}$} \\
\hline & \multirow{2}{*}{\multicolumn{2}{|c|}{$\begin{array}{l}\text { G. quinine } \\
\text { bisulfate } \\
\text { added } \\
\text { as } 1 \% \\
\text { t. solution. }\end{array}$}} & \multirow{2}{*}{$\begin{array}{c}\text { Volume of } \\
\text { mixture. } \\
\text { Cc. }\end{array}$} & \multicolumn{2}{|c|}{ After $1 / 2 \mathrm{hr}$, rotation. } & \\
\hline & & & & $\begin{array}{l}\text { G. displaced } \\
\text { methyletie blue. }\end{array}$ & $\begin{array}{c}\text { G. adsorbed } \\
\text { quinine bisulfate. }\end{array}$ & \\
\hline I.O & 0.10 & 0.10 & 100 & 0.000 & 0.100 & 0.20 \\
\hline 1.0 & 0.15 & 0.15 & 100 & 0.000075 & 0.104 & 0.254 \\
\hline 1.0 & 0.20 & 0.25 & 100 & 0.00016 & 0.076 & 0.276 \\
\hline 1.0 & 0.21 & 0.40 & 100 & 0.000175 & 0.072 & 0.282 \\
\hline
\end{tabular}

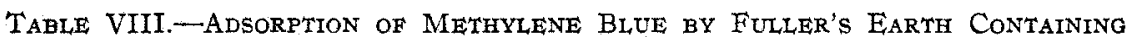
ADSORBED QUININE BISUlFatE.

\begin{tabular}{|c|c|c|c|c|c|c|}
\hline \multirow[b]{2}{*}{$\begin{array}{l}\text { G. } \\
\text { original } \\
\text { fuller's } \\
\text { earth. }\end{array}$} & \multirow[b]{2}{*}{$\begin{array}{l}\text { G. adsorbed } \\
\text { quinine } \\
\text { bisulfate } \\
\text { present. }\end{array}$} & \multirow[b]{2}{*}{$\begin{array}{l}\text { G. methyl- } \\
\text { ene blue } \\
\text { added as } 0.5 \\
\text { \% solution. }\end{array}$} & \multirow[b]{2}{*}{$\begin{array}{c}\text { Volume } \\
\text { of } \\
\text { mixture. } \\
\text { Cc. }\end{array}$} & & \multirow[b]{2}{*}{$\begin{array}{c}\text { methylene } \\
\text { blue }+ \\
\text { quinine } \\
\text { bisulfate } \\
\text { adsorbed. }\end{array}$} \\
\hline & & & & $\begin{array}{c}\text { G. } \\
\text { displaced } \\
\text { quinine } \\
\text { bisulfate. }\end{array}$ & $\begin{array}{c}\text { G. } \\
\text { adsorbed } \\
\text { methylene } \\
\text { blue. }\end{array}$ & \\
\hline 1.0 & 0.18 & 0.09 & 80 & 0.017 & 0.090 & 0.253 \\
\hline 1.0 & 0.232 & 0.12 & 80 & 0.023 & 0.1198 & 0.329 \\
\hline 1.0 & 0.283 & 0.20 & 80 & 0.059 & 0.1643 & 0.388 \\
\hline 1.0 & 0.309 & 0.30 & 80 & 0.088 & 0.1950 & 0.416 \\
\hline
\end{tabular}

Effect of Dilution with Water on the Adsorption of Quinine Bisulfate by Fuller's Earth. -This experiment was made by rotating mixtures of the compositions shown in Table IX for the usual one-half hour period, filtering quickly through Gooch crucibles and titrating the unadsorbed quinine bisulfate in the filtrates with $0.02 N$ sodium hydroxide, using phenolphthalein as indicator. The volumes of the solutions varied from I5 cc. to $90 \mathrm{cc}$. in the case where $0.15 \mathrm{~g}$. quinine bisulfate per $1.0 \mathrm{~g}$. of fuller's earth had been used and from 30 to $90 \mathrm{cc}$. where $0.3 \mathrm{~g}$. of the alkaloidal salt was present. Control titrations showed that the end point was affected very slightly by increase of dilution and a correction was applied for this. It will be observed that at the lower ratio of alkaloid to fuller's earth the effect of increasing the volume of water is practically negligible. At the higher ratio it is still not of sufficient magnitude to be of consequence in the practical utilization of fuller's earth for chemical separations. It appears that, if sufficient fuller's earth is present to adsorb all the alkaloid in a small volume of solution, a very considerable dilution with water does not appreciably diminish the adsorbing power of the

${ }^{1}$ Estimated indirectly from total solids determinations. 
earth. When insufficient fuller's earth is used to completely adsorb all of the alkaloid present, an increase in dilution appreciably reduced the proportion of alkaloid which is adsorbed. To insure complete adsorption at any dilution, it is, therefore, only necessary to use that amount of fuller's earth which has been found at low dilutions to be sufficient to adsorb all the material without leaving any unadsorbed.

TABLE IX.-SHOWING THE EFFECT OF DILUTION WITH WATER UPON THE ADSORPTION OF QUININE Bisulfate by Fullek's Earth.

(Mixtures rotated one-half hour and filtered through Gooch crucible.)

$\begin{array}{cccc}\begin{array}{c}\text { G. English } \\ \text { fuller's earth. }\end{array} & \begin{array}{c}1 \% \text { quinine bisul- } \\ \text { fate solution. }\end{array} & \begin{array}{c}\mathrm{H}_{2} \mathrm{O} \\ \text { added. Cc. }\end{array} & \begin{array}{c}\text { G. quinine b } \\ \text { fate adsorbed } \\ \text { 1.0 g. fuller's }\end{array} \\ \text { I.O } & \text { I5 } & 0 & 0.149 \\ \text { I.O } & 15 & 15 & 0.148 \\ \text { I.O } & 15 & 75 & 0.147 \\ \text { I.O } & 30 & 0 & 0.263 \\ \text { I. } & 30 & 30 & 0.252 \\ \text { I.O } & 30 & 60 & 0.250\end{array}$

Effect of Acidity on the Adsorption of Quinine Bisulfate by Fuller's Earth.-As pointed out in a previous section of this paper, when either quinine bisulfate or methylene blue is shaken with fuller's earth only the base in each case is adsorbed and the liberated acid unites with calcium from the earth and remains in the aqueous solution. It, therefore, appeared of interest to ascertain the effect of increasing acidity upon this reaction.

TABLE X.-EFFect of Hydrochloric Acid on the Adsorption of Quintse BISULFATE BY FULLER'S EARTH.

(Each mixture rotated one-half hour and the solid removed by centrifugation.)

$\begin{array}{ccccc}\begin{array}{c}\text { G. } \\ \text { English } \\ \text { fuller's } \\ \text { earth. }\end{array} & \begin{array}{c}\text { Quinine } \\ \text { bisulfate. }\end{array} & \begin{array}{c}\text { Volume } \\ \text { mixture. }\end{array} & \begin{array}{c}\text { Cormality } \\ \text { HCl. }\end{array} & \begin{array}{c}\text { G. quinine bi- } \\ \text { sulfate adsorbed } \\ \text { per I.0 g. } \\ \text { fuller's earth. }\end{array} \\ \text { I.O } & 0.15 & 50 & 0.000 & 0.148 \\ \text { I.O } & 0.15 & 50 & 0.004 & 0.148 \\ \text { I.O } & 0.15 & 50 & 0.020 & 0.145 \\ \text { I.O } & 0.15 & 50 & 0.10 & 0.143 \\ \text { I.O } & 0.15 & 50 & 0.40 & 0.135 \\ \text { I.O } & 0.30 & 50 & 0.000 & 0.256 \\ \text { I.O } & 0.30 & 50 & 0.004 & 0.232 \\ \text { I.O } & 0.30 & 50 & 0.020 & 0.206 \\ \text { I.O } & 0.30 & 50 & 0.10 & 0.196 \\ \text { I.O } & 0.30 & 50 & 0.40 & 0.201\end{array}$

Mixtures were prepared as shown in Table $\mathrm{X}$ and the solutions obtained after removing the solid by centrifugation were used for the determination of unadsorbed quinine bisulfate. The analytical procedure was as follows: Aliquot portions of the aqueous solutions were evaporated to dryness, to remove excess of hydrochloric acid. The residues were just neutralized with aqueous sodium hydroxide and again evaporated to dryness. They 
were then extracted with absolute alcohol and the alcoholic extracts evaporated to dryness. These were treated with hydrochloric acid to yield quinine dihydrochloride and after repeated evaporations to remove excess of acid, the alkaloidal salt was titrated ${ }^{1}$ with $0.0 \mathrm{I} N \mathrm{NaOH}$ and the corresponding amount of quinine bisulfate calculated from these titrations. The quantities of quinine bisulfate thus found were subtracted from the amounts of this salt originally present, and the differences given in Table $\mathrm{X}$ as the $\mathrm{g}$. adsorbed per $\mathrm{I}$.o g. of fuller's earth.

These results show that in the case of the ratio of $0.15 \mathrm{~g}$. of quinine salt per r.o g. of fuller's earth, which is very near the quantity just completely adsorbed in water alone, the increase of acidity has relatively much less effect in diminishing the adsorption than when the ratio is $0.3 \mathrm{~g}$. salt per r.o g. of fuller's earth.

As in the case of the dilution experiment, the retarding effect here is of no serious consequence, provided the amount of fuller's earth used is sufficient for complete adsorption of the amount of alkaloid present.

Effect of Ethyl Alcohol on the Adsorption of Quinine Bisulfate and of Methylene Blue by Fuller's Earth.--In this as in the other experiments, two ratios of fuller's earth to material to be adsorbed were selected, one being that at which almost complete adsorption occurs and the other representing insufficient earth to adsorb all the alkaloid or methylene blue present. The results are shown in Tables XI and XII. It is seen that little effect is produced by the alcohol when the larger proportion of fuller's earth is present, but that the reduction caused by the alcohol in the other case is quite marked. It is, therefore, apparent that, even in presence of very large quantities of alcohol, complete adsorption can be obtained provided fuller's earth is used in the proper proportion.

\section{TABle XI.-EFfect of EThyl Alcohol on The Adsorption of Quintne Bisulfate BY FULLER'S EARTH.}

(Each mixture rotated one-half hour and the solid removed by centrifugation.)

$\begin{array}{ccccc}\begin{array}{c}\text { G. English } \\ \text { fuller's earth. }\end{array} & \begin{array}{c}\text { G.quinine } \\ \text { bisulfate. }\end{array} & \begin{array}{c}\text { Volume of } \\ \text { mixture. Cc. }\end{array} & \begin{array}{c}\text { Vol. } \\ \text { in mixture. }\end{array} & \begin{array}{c}\text { G. quinine bi- } \\ \text { sulfate adsorbed per } \\ 1.0 \text { g. fuller's earth. }\end{array} \\ \text { I.O } & 0.15 & 50 & 10 & 0.149 \\ 1.0 & 0.15 & 50 & 20 & 0.148 \\ \text { I.O } & 0.15 & 50 & 40 & 0.147 \\ \text { I.O } & 0.15 & 50 & 70 & 0.147 \\ \text { I.O } & 0.30 & 50 & 10 & 0.265 \\ 1.0 & 0.30 & 50 & 20 & 0.257 \\ 1.0 & 0.30 & 50 & 40 & 0.228 \\ 1.0 & 0.30 & 50 & 70 & 0.22 I\end{array}$

${ }^{1}$ Method of E. Elvove, "Fixing Power of Alkaloids for Volatile Acids and Its Application to the Estimation of Alkaloids with the Aid of Phenolphthalein or by the Volhard Method," Hyg. Lab. Bull., P. H. S., 54, 1909. 
Tabie XII.-EFfect of Ethyl Alcohol on the Adsorption of Methylene Blut BY FULLER'S EARTH.

(Each mixture rotated one-half hour and the solid removed by centrifugation.)

$\begin{array}{ccccc}\begin{array}{c}\text { G. English } \\ \text { fuller's earth. }\end{array} & \begin{array}{c}\text { G. methylene } \\ \text { blue. }\end{array} & \begin{array}{c}\text { Volume of } \\ \text { mixture. Ce. }\end{array} & \begin{array}{c}\text { Vol. } \\ \text { in mixture. } \\ \text { in mixture. }\end{array} & \begin{array}{c}\text { G. methylene } \\ \text { blue adsorbed per } \\ \text { 1.0 g. fuller's earth. }\end{array} \\ 0.5 & 0.075 & 50 & 50 & 0.1497 \\ 0.5 & 0.075 & 50 & 20 & 0.1497 \\ 0.5 & 0.075 & 50 & 40 & 0.1495 \\ 0.5 & 0.075 & 50 & 70 & 0.1486 \\ 0.5 & 0.150 & 50 & 10 & 0.2330 \\ 0.5 & 0.150 & 50 & 20 & 0.2334 \\ 0.5 & 0.150 & 50 & 40 & 0.2270 \\ 0.25 & 0.075 & 50 & 70 & 0.1976\end{array}$

Effect of Cane Sugar on the Adsorption of Quinine Bisulfate by Fuller's Earth.-This experiment was made in the same manner as the preceding. The results are given in Table XIII and show that almost no reduction of the adsorption occurs when either the higher or the lower ratio of fuller's earth is used.

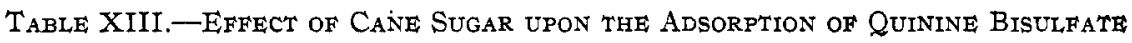
BY FULLER'S EARTF.

(Each mixture rotated one-half hour and the solid removed by centrifugation.)

$\begin{array}{cc}\begin{array}{c}\text { G. English } \\ \text { fuller's } \\ \text { earth. }\end{array} & \begin{array}{c}\text { G. quinine } \\ \text { bisulfate. }\end{array} \\ \text { I.O } & 0.15 \\ \text { I.O } & 0.15 \\ \text { I.O } & 0.15 \\ \text { I.O } & 0.15 \\ \text { I.O } & 0.30 \\ \text { I.O } & 0.30 \\ \text { I.O } & 0.30 \\ \text { I.O } & 0.30\end{array}$

G. can
sugar
2.5
5.0
IO.0
I 7.5
2.5
5.0
IO.O
I 7.5

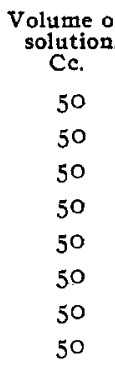

G. quinine bisulfate adsorbed per $1.0 \mathrm{~g}$. fuller's earth.

$$
\begin{aligned}
& 0.145 \\
& 0.143
\end{aligned}
$$$$
\text { o. } 144
$$$$
\text { o. } 144
$$$$
\text { ○. } 257
$$$$
\text { ○. } 257
$$$$
\text { 0. } 256
$$$$
0.254
$$

Summary.

A comparison of the adsorptive capacities of 36 samples of fuller's earths and other clays showed that English earth is superior to any of the domestic fuller's earths except one, the exact source of which could not be learned. Domestic bentonite exhibits a higher adsorptive power than the English samples of fuller's earth, but on account of its exceptional capacity for retaining water, it cannot be used to advantage in cases, such as the present, where a sharp separation of solid and solution is essential.

It was found that the adsorption of quinine bisulfate and methylene blue by fuller's earth increased with time of contact but at a gradually diminishing rate. It was also found that the amounts adsorbed continued to increase with amount of excess present. Maxima were not observed in the case of either the time factor or the concentration factor. 
In the case of both quinine bisulfate and of methylene blue the free base only is adsorbed from the aqueous solution when brought in contact with fuller's earth. The acid component of each compound unites with calcium derived from the fuller's earth and remains in the aqueous solution.

When equal amounts of quinine bisulfate and methylene blue are simultaneously present in an aqueous solution shaken with fuller's earth, both compounds are adsorbed to approximately the same extent. The sum of the two components is about $25 \%$ greater than the amount of either adsorbed separately.

When the same portion of fuller's earth is first shaken with methylene blue and then with quinine bisulfate, a small amount of the latter compound is taken up and only a trace of the former liberated. When the procedure is reversed, considerably more methylene blue is adsorbed and a fairly large proportion of the quinine bisulfate is displaced from its combination with the fuller's earth. The results show that under the special conditions of this experiment, fuller's earth exhibits a distinct preference for methylene blue.

Dilution of the aqueous solution, in the case of quinine bisulfate, does not diminish appreciably the amount adsorbed when the ratio of earth to alkaloid is approximately that required for complete adsorption. In the case of a ratio of earth which is insufficient for complete adsorption, dilution causes a distinct reduction in the amount adsorbed.

Increase of acidity of the aqueous solution, likewise, does not diminish the amount of quinine adsorbed in case the ratio of earth is just sufficient for complete adsorption. With less earth than sufficient for complete adsorption a distinct reduction in the amount of adsorbed alkaloid follows an increase in acidity of the aqueous medium.

Ethyl alcohol diminishes the adsorption only in cases where the ratio of earth used is insufficient for complete removal of quinine or of methylene blue.

The presence of quite large amounts of cane sugar was found to exert no retarding influence upon the adsorption of quinine bisulfate by fuller's earth.

In conclusion it appears that the adsorptive power of fuller's earth is exerted particularly towards certain compounds, characterized by distinct basicity and that in the case of salts, only the base unites with the fuller's earth. No marked selectivity was found in the case of the two compounds forming the basis of the present experiments. The amount adsorbed in a given time is a function of ratio of earth to adsorbable material and except with insufficient earth for complete adsorption, is independent of dilution, acidity or presence of non-adsorbable neutral material.

W ASEINGTON, D. C. 